\title{
EVALUASI SISTEM INFORMASI UNTUK MENILAI PROSES DELIVER DAN SUPPORT DALAM KEGIATAN PENELITIAN DAN PENGEMBANGAN DI PUSLIT TELIMEK LIPI
}

\author{
Muhammad Benny Chaniago \\ Program Studi Sistem Informasi Universitas Widyatama \\ J1. Cikutra No. 204A Bandung \\ benny.chaniago@widyatama.ac.id
}

\begin{abstract}
Abstrak
Puslit Telimek LIPI telah menerapkan Tata Kelola TI dalam proses bisnisnya dan bermaksud mengembangkan bisnis yang sudah berjalan untuk lebih baik lagi. Namun sebelum hal ini diputuskan, diperlukan suatu kajian mendalam mengenai kesesuaian layanan TI yang tersedia terhadap prioritas bisnis, optimalisasi pembiayaan TI dan penelitian untuk membuktikan bahwa sistem yang tersedia telah dapat digunakan oleh karyawan secara produktif. Oleh karena itu diperlukan pengukuran terhadap kinerja TI untuk mendeteksi permasalahan sebelum meluas dan membesar. Domain Deliver dan Support (DS) yang terdapat dalam framework COBIT digunakan untuk mengevaluasi kinerja TI tersebut. Hasil penelitian menunjukkan bahwa dilihat pada current maturity level yaitu DS1, DS2, DS3, DS4, DS5, DS6, DS7, DS8, DS9, DS10 dan DS11 berada pada tingkat kematangan Repeatable but Intuitive sedangkan DS12 dan DS13 berada pada tingkat yang lebih rendah, yakni pada tingkat kematangan Initial/Ad Hoc. Hasil penelitian ini diharapkan menjadi sebuah masukan dan rekomendasi untuk peningkatan efisiensi dan efektifitas TI yang selaras dengan bisnis, dapat menjawab kebutuhan bisnis serta dapat membantu eksekutif untuk memahami dan mengelola investasi TI dalam mendukung manajemen inovasi.
\end{abstract}

Kata kunci :

Tata Kelola TI, Domain DS, COBIT, Maturity Level, Repeatable but Intuitive, Initial/Ad Hoc

\begin{abstract}
Puslit Telimek LIPI has implemented IT Governance in the business process and intends to develop a business that has been running for the better. But before this is decided, needed an in-depth study on the suitability of IT services available to business priorities, optimization of finance IT and research to prove that the systems available have been used by employees productively. Therefore we need a measurement of IT performance to detect problems before they escalate and expand. Deliver and Support domain contained in the COBIT framework is used to evaluate the performance of IT and the results can be seen on the current maturity level DS1, DS2, DS3, DS4, DS5, DS6, DS7, DS8, DS9, DS10 and DS11 are at maturity level Repeatable but Intuitive while the DS12 and DS13 are at a lower level, ie at maturity level Initial/Ad Hoc. From the results of measurements in this study is expected to be a recommendations for improving the efficiency and effectiveness of IT is aligned with business, can answer the needs of the business and can help executives to understand and manage IT investments in support of innovation management.
\end{abstract}

Keywords :

IT Governance, Deliver and Support Domain, COBIT, Maturity Level, Repeatable but Intuitive, Initial / Ad Hoc 


\section{Pendahuluan}

Peningkatan pertumbuhan ekonomi negara yang berkelanjutan sangat bergantung pada kemampuannya dalam meningkatkan inovasi. Inovasi yang berlandaskan pada produk riset teknologi akan memberikan dampak secara langsung pada peningkatan produktivitas yang berkelanjutan yang pada akhirnya dapat mempercepat pertumbuhan ekonomi negara. Kemampuan menguasai ilmu pengetahuan dan teknologi (IPTEK) menjadi suatu keharusan untuk dapat menghasilkan sebuah inovasi yang sangat bermanfaat untuk pengembangan ekonomi agar dapat bersaing secara global.

Inovasi erat kaitannya dengan pengetahuan, kreativitas, desain, invensi, perubahan, kegagalan, eksploitasi, kewirausahaan, pelanggan, pertumbuhan, dan sosial. Proses inovasi dapat diekspresikan memakai sebuah model yang terdiri dari tiga tahap yaitu: pencarian ide dan seleksi, realisasi ide, dan komersialisasi hasil. Ide-ide inovasi dapat dihasilkan melalui dua pendekatan yaitu: didorong lahirnya teknologi baru (technology push) dan ditarik oleh kebutuhan pasar (market pull).

Kegiatan penelitian dan pengembangan (litbang) adalah bagian mata rantai penting dalam proses inovasi. Pemerintah Indonesia memiliki beberapa lembaga litbang baik berbentuk LPNK yang berada di bawah koordinasi Kementrian Riset dan Teknologi (KRT) maupun berbentuk Badan Litbang di bawah kementrian teknis. Kinerja masing-masing lembaga litbang dapat dilihat pada pencapaian Indikator Kinerja Utama mereka, dan sebagai bagian dari lembaga milik pemerintah maka mereka diwajibkan melaksanakan Reformasi Birokrasi (RB).

Teknologi Informasi dan Komunikasi (TIK) diyakini dapat membantu pelaksanaan program RB di atas sehingga sebuah satuan kerja di bawah lembaga litbang milik pemerintah dapat mengelola organsiasi secara lebih efisien dan efektif dalam meningkatkan kinerjanya sesuai dengan Indikator Kinerja Utamanya.

Sebagai lembaga milik pemerintah, Puslit Telimek LIPI diwajibkan melaksanakan agenda Reformasi Birokrasi (RB). Teknologi Informasi dan Komunikasi (TIK) diyakini dapat membantu meningkatkan efisiensi, efektifitas dan produktifitas organisasi yang menjadi salah satu tuntutan RB. Di Puslit Telimek LIPI sistem informasi dikelola pada Sub Bagian Jasa dan Informasi.
Rumusan permasalahan yang akan dibahas pada penelitian ini adalah Puslit Telimek LIPI telah menerapkan Tata Kelola TI dalam proses bisnisnya dan ingin mengembangkan bisnis yang sudah berjalan untuk berkembang lebih baik lagi. Namun sebelum hal ini diputuskan, diperlukan suatu kajian mendalam mengenai kesesuaian layanan TI yang tersedia dengan prioritas bisnis, optimalisasi pembiayaan TI dan penelitian untuk membuktikan bahwa sistem yang tersedia telah dapat digunakan oleh karyawan secara produktif. Oleh karena itu diperlukan pengukuran terhadap kinerja TI untuk mendeteksi permasalahan sebelum meluas dan membesar. Pengawasan internal oleh manajemen terhadap TI harus berjalan secara efektif dan efisien, keterkaitan kinerja TI dengan tujuan bisnis, kerahasiaan, integritas dan ketersediaan informasi dapat terjamin.

Tujuan penelitian ini untuk melakukan suatu pengukuran terhadap sistem informasi di Puslit Telimek LIPI dengan menggunakan framework COBIT. Dengan pengukuran tersebut diharapkan hasil dari penelitian ini adalah sebuah kesimpulan dan rekomendasi untuk peningkatan efisiensi dan efektifitas TI yang selaras dengan bisnis, dapat menjawab kebutuhan bisnis dan dapat membantu eksekutif untuk memahami dan mengelola investasi TI dalam mendukung manajemen inovasi.

Penelitian ini diharapkan dapat memberikan penilaian terhadap sistem informasi pada Puslit Telimek LIPI, agar dapat diambil suatu tindakan koreksi berdasarkan kesimpulan dan rekomendasi yang dihasilkan dalam penelitian ini yang bertujuan untuk meningkatkan efisiensi dan efektifitas TI agar lebih selaras dengan bisnis, dapat menjawab kebutuhan bisnis dan membantu eksekutif untuk memahami dan mengelola investasi TI dalam mendukung manajemen inovasi.

Secara umum penelitian ini diharapkan dapat memberikan sumbangan bagi pengembangan dan penerapan Tata Kelola TI di Indonesia dan dapat digunakan sebagai percontohan evaluasi sistem informasi bagi perusahaan. 


\section{KAJIAN LITERATUR}

\section{II.1 Penelitian Terdahulu}

Berdasarkan hasil telaah terhadap penelitian yang berkaitan dengan tata kelola TI (IT Governance), terdapat beberapa hasil penelitian yang dapat dijadikan dasar acuan kajian ini, antara lain:

1. (Gomes, Ribeiro, 2009), dalam papernya yang berjudul "The Main Benefits of COBIT in a High Public Educational Institution - A Case Study", menggambarkan implementasi COBIT di sebuah perguruan tinggi di Portugal Utara yang memiliki beberapa sistem informasi yang tersebar dan mendukung aktivitas perguruan tinggi tersebut. Oleh karena itu diperlukan suatu mekanisme yang menjamin manajemen dan pengendalian dari sistem informasi khususnya untuk tata kelola TI. Sebagai bagian dari penerapan Sistem Manajemen Mutu IPVC dalam pelaksanaan sertifikasi standar ISO 9001, dilaksanakan pedoman COBIT untuk memastikan sertifikasi. Berikutnya digunakan COBIT dalam mengimplementasikan mekanisme untuk membangun tata kelola TI terutama dalam mengelola dan mengendalikan TI serta sistem informasi. Gomes menyimpulkan bahwa COBIT merupakan kerangka kerja yang cocok untuk pelaksanaan sertifikasi standar ISO 9001 dan untuk tata kelola TI di lembaga pendidikan publik di bidang SI dan TI. Dengan implementasi ini lembaga kualitas layanan telah meningkat secara signifikan, mengurangi jumlah anomali dan memberikan mekanisme lebih efisien untuk mengelola dan mengontrol berbagai sistem informasi mereka, mampu meningkatkan kualitas kehadiran, mengurangi waktu eksekusi sekitar 25\%. Efisien dalam memantau dan mengendalikan infrastruktur komponen teknologi, jumlah insiden diselesaikan oleh departemen TI berkurang sekitar 30\% dan mengurangi lebih dari 10\% insiden yang berulang.

2. (Brave, 2010), melakukan studi kasus nyata mengenai penggunaan COBIT untuk manajemen resiko dalam organisasi bank. Bank yang dijadikan contoh kasus dalam studi ini adalah sebuah bank konglomerat yang beroperasi di 50 negara dengan lebih dari 12 ribu karyawan. Team TI dari bank tersebut dialokasikan di seluruh penjuru dunia untuk mendukung bisnis. Tata kelola teknologi dirancang melalui kerangka kerja manajemen resiko yang efektif untuk menjamin manajemen dan pengendaliannya. Kerangka tersebut didefinisikan untuk mengetahui resiko dan manajemen pengendalian yang ada seperti :

a. Proses yang belum membuahkan hasil untuk penilaian dan pengujian kepatuhan.

b. Kurangnya pengendalian tunggal terhadap repository, menghasilkan duplikasi kontrol.

c. Kurangnya proses yang jelas dan berulang untuk memenuhi penilaian resiko. Kerangka baru diharapkan dapat membuat team teknologi memahami resiko operasional yang signifikan dan dampaknya yang lebih luas di dalam organisasi dengan :

1) Mengatasi area di mana resiko tidak dikontrol secara efektif.

2) Mengizinkan eksekutif teknologi untuk menunjukkan tanggung jawab secara regulasi dengan efisien.

3) Menggunakan platform umum untuk membuat laporan semua persyaratan peraturan di daerah dan negara lain.

4) Melaporkan resiko teknologi dan kelemahan kontrol yang mungkin berdampak kepada bisnis secara efektif.

5) Menerapkan proses standar di seluruh wilayah dan kantor untuk memastikan konsistensi dan menghindari duplikasi laporan.

Tim pemerintah memutuskan untuk menggunakan COBIT sebagai kerangka kerja standar. Team ini terdiri dari para profesional termasuk di bidang resiko, keamanan TI dan ahli proses US Sarbanez-Oxley. Team dibentuk untuk mendefinisikan proses dan template. Team mendapatkan tugas yang utama berada di area untuk :

a. Mendefinisikan sebuah kerangka kerja yang akan digunakan.

b. Mengidentifikasi sebuah definisi standar dari entity yang melawan resiko dan kontrol yang akan dievaluasi.

c. Mengidentifikasi proses manajemen resiko.

\section{II.2 Sistem Informasi}

Sistem adalah kumpulan sumber daya atau elemen-elemen dan jaringan prosedur yang saling terkait secara terpadu, terintegrasi dalam suatu hubungan hirarkis tertentu dan bertujuan untuk 
mencapai tujuan tertentu. Sedangkan informasi adalah data yang diolah agar menjadi lebih berguna bagi para pemakainya. Jadi dengan demikian yang dimaksud dengan "untuk mencapai tujuan tertentu" pada definisi sistem informasi tadi adalah mengolah data menjadi informasi (yang bermaksud bagi para penggunanya). Dengan demikian sistem informasi dapat didefinisikan sebagai kumpulan elemen-elemen atau sumber daya dan jaringan prosedur yang saling berkaitan secara terpadu, terintegrasi dalam suatu hubungan hirarkis tertentu, dan bertujuan untuk mengolah data menjadi informasi.

Muhammad Fakhri Husein dan Amin Wibowo dalam (Gondodiyoto, 2007) menyatakan bahwa sistem informasi didefinisikan sebagai: "...seperangkat komponen yang saling berhubungan dan berfungsi mengumpulkan, memproses, menyimpan dan mendistribusikan informasi untuk mendukung pembuatan keputusan dan pengawasan dalam organisasi." Sistem informasi sangat diperlukan para manajer organisasi guna melaksanakan tugas khusus tertentu yang sangat esensial bagi berfungsinya organisasi. Tugas ini berkisar sejak pengolahan data yang sederhana, seperti menyiapkan tagihan kepada pelanggan, hingga kecanggihan analisis yang digunakan oleh para manajer untuk pengambilan keputusan dalam menyiapkan basis kegiatan organisasi.

\section{II.3 Teknologi Informasi}

Teknologi informasi mencakup perangkat keras dan perangkat lunak untuk melaksanakan satu atau sejumlah tugas pemrosesan data seperti menangkap, mentransmisikan, menyimpan, mengambil, memanipulasi atau menampilkan data.

Menurut (Deeson, 1991), “Information Technology (IT) is the handling of information by electric and electronic (and microelectronic) means. Here handling includes transfer, processing, storage and access. IT special concern being the use of hardware and software for these tasks for the benefit of individual people and society as a whole".

Teknologi informasi adalah segala bentuk teknologi yang diterapkan untuk memproses dan mengirimkan informasi dalam bentuk elektronis. Teknologi ini menggunakan seperangkat komputer untuk mengolah data, sistem jaringan untuk menghubungkan satu komputer dengan komputer lainnya sesuai dengan kebutuhan, dan teknologi telekomunikasi digunakan agar data disebar dan diakses secara global, seperti gambar di bawah ini.

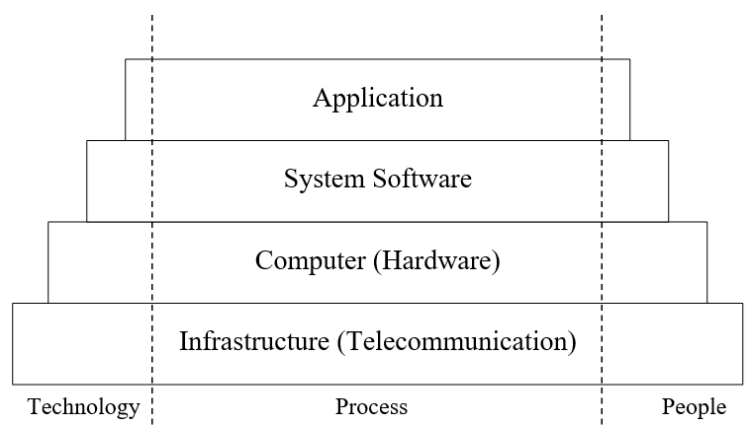

\section{Gambar 1. Arsitektur Teknologi Informasi} (Kadir, 2003)

Perkembangan teknologi informasi memacu suatu cara baru kehidupan, dari kehidupan dimulai sampai dengan berakhir, kehidupan seperti ini dikenal dengan e-life, artinya kehidupan ini sudah dipengaruhi oleh berbagai kebutuhan secara elektronik. Dan sekarang ini sedang semarak dengan berbagai huruf yang dimulai dengan awalan e seperti e-business, e-commerce, e-government, e-education, $e$-library, dan lainnya lagi yang berbasis elektronik.

\section{II.4 Tata Kelola TI}

(Sarno, 2009) menyatakan bahwa Tata Kelola TI terdiri dari sistem informasi, teknologi dan komunikasi, bisnis dan hukum serta isu-isu lain yang melibatkan seluruh stakeholder. Penyusunan tata kelola TI merupakan tanggung jawab dari direksi dan manajemen eksekutif.

Pada dasarnya, elemen kunci dari tata kelola TI adalah penyerasan bisnis dan TI yang mengarahkan pada pemenuhan nilai bisnis. Fokus utama dari area Tata Kelola TI dapat dibagi menjadi lima area yaitu :

a. Penyelarasan strategis (strategic alignment) yang memfokuskan pada keterkaitan antara strategi bisnis dan TI serta penyelarasan antara operasional TI dengan bisnis.

b. Penyampaian nilai (value delivery) yang mencakup pada hal-hal yang berkaitan dengan penyampaian nilai bahwa TI dapat memenuhi manfaat dalam pengoptimalan biaya dan pembuktian nilai hakiki akan keberadaan TI.

c. Pengelolaan sumber daya (resource management) yang berkaitan dengan 
pengoptimalan investasi dalam pengoptimalan pengetahuan dan infrastruktur.

d. Pengelolaan resiko (risk management) yang membutuhkan kepekaan akan seluruh resiko oleh manajemen senior sehingga dapat dipahami proses bisnis perusahaan dan tanggung jawab pengelolaan resiko ke dalam organisasi itu sendiri.

e. Pengukuran kinerja (performance measurement) yang berfokus pada penelusuran dan pengawasan implementasi dari strategi, pemenuhan proyek yang berjalan, penggunaan sumber daya, kinerja proses dan penyampaian layanan.

\section{II.5 Audit Sistem Informasi}

Audit merupakan suatu proses sistematis yang melakukan kegiatan pengumpulan dan evaluasi bukti secara objektif mengenai pertanyaan-pertanyaan yang berhubungan dengan tindakan ekonomi maupun suatu kejadian, kemudian dilakukan perbandingan antara pernyataan tersebut dengan kriteria yang telah ditetapkan, dan menginformasikan hasilnya pada pihak yang berkepentingan sebagai bahan evaluasi dan pengembangan di kemudian hari.

Menurut (Weber, 1999), "Information system auditing is the process of collecting and evaluating evidence to determine whether a computer system safeguards assets, maintains data integrity, allow organizational goals to be achieved effectively, and uses resources efficiently".

Apabila disimpulkan definisi tadi maka dapat disimpulkan sekurang-kurangnya terdapat empat tujuan audit sistem informasi yaitu mengamankan asset, menjaga integritas data, menjaga efektivitas sistem, dan mencapai efisiensi sumber daya.

Audit dianggap efektif ketika sistem sudah berjalan selama beberapa waktu tertentu melalui auditor dengan melakukan post audit untuk menentukan sejauh mana sistem telah mencapai tujuan yang telah ditetapkan. Dan hasilnya dapat menjadikan masukan bagi pengambil keputusan untuk menentukan kebijakan berikutnya seperti kinerja sistem masih layak dipertahankan, perlu diperbaharui, atau sistem sudah usang sehingga harus ditinggalkan dan dicari penggantinya.

\section{II.6 Model Audit}

Saat ini sudah cukup banyak model audit TI yang sudah siap digunakan. Berikut adalah beberapa dari model framework yang banyak digunakan di dunia yaitu ITIL (The IT Infrastructure Library), ISO/IEC 17799 (The International Organization for Standardization/The International Electrotechnical Commission), COSO (Committee of Sponsoring Organization of the Treadway Commision), dan COBIT (Control Objectives for Information and realted Technology).

\section{II.6.1 ITIL}

ITIL dikembangkan oleh The Office of Government Commerce (OGC) suatu badan dibawah pemerintah Inggris, dengan bekerja sama dengan The IT Service Management Forum (ITSMF) - suatu organisasi independen mengenai manajemen pelayanan teknologi informasi - dan British Standard Institute (BSI) - suatu badan penetapan standar pemerintah Inggris.

ITIL bukan merupakan standar dalam audit TI. ITIL lebih merupakan framework/best practice bagi IT service management untuk menciptakan layanan teknologi informasi yang bermutu tinggi. ITIL terdiri atas delapan buku berseri yang disusun dan diterbitkan oleh Central Computer and Telecommunications Agency (CCTA) yang sekarang dikenal sebagai The British Office of Government Commerce (OGC). Delapan serial buku ITIL tersebut terdiri atas:
a. Software Asset Management
b. Service Support
c. Service Delivery
d. Planning to Implement Service Management
e. ICT Infrastructure Management
f. Application Management
g. Security Management

\section{II.6.2 ISO/IEC 17799}

ISO/IEC 17799 Code of Practice for Information Security Management adalah standar internasional yang dirilis pertama kali pada Desember 2000. Tujuan utama dari penyusunan standar ini adalah penerapan keamanan informasi dalam organisasi. Framework ini diarahkan untuk mengembangkan dan memelihara standar keamanan dan praktek manajemen dalam organisasi untuk meningkatkan ketahanan (reliability) bagi keamanan informasi dalam hubungan antar organisasi. Dalam framework ini didefinisikan 11 bagian besar yang terbagi dalam 132 strategi kontrol keamanan. Standar ini lebih menekankan pada pentingnya manajemen resiko dan tidak menuntut penerapan pada setiap 
komponen tapi dapat memilih pada bagian-bagian yang terkait saja.

Sejak edisi keduanya terbit pada 2005, ISO/IEC 17799 Code of Practice for Information Security Management menjadi standar resmi ISO yang berdampak pada diperlukannya revisi dan pemutakhiran setiap tiga hingga lima tahun sekali. Pada April 2007, ISO memasukkan framework ini ke dalam ISO 2700x series, Information Security Management System sebagai ISO 27002. Standar tersebut dapat digolongkan dalam best practice termutakhir dalam lingkup sistem manajemen keamanan informasi.

\section{II.6.3 COSO}

COSO adalah organisasi swasta yang menyusun Internal Control - Integrated Framework bagi peningkatan kualitas penyampaian laporan keuangan dan pengawasal internal untuknya yang lebih efektif. Tujuan dari penyusunan framework ini adalah peningkatan sistem pengawasan terpadu untuk pengendalian perusahaan/organisasi dalam beberapa langkah. Hal ini diarahkan untuk memberikan para pemegang kebijakan di organisasi dapat melakukan pengawasan internal dalam pelaksanaan tugas kepada para eksekutif, mencapai laba yang menguntungkan serta mengelola resiko-resiko yang timbul. Internal Control - Integrated Framework yang disusun oleh COSO diterbitkan pertama kali pada 1992 dan masih diperbaharui hingga saat ini. Hingga saat ini COSO maupun organisasi lainnya tidak melakukan / menerbitkan sertifikasi keahlian / professional bagi framework ini.

Lingkup criteria informasi yang sering menjadi perhatian dalam Internal Control - Integrated Framework COSO adalah:

a. Effectiveness

b. Efficiency

c. Confidentiality

d. Integrity

e. Availability

f. Compliance

g. Reliability

\section{II.6.4 COBIT}

Pada 1998 ITGI (IT Governance Institute) didirikan dengan tujuan untuk memajukan pemikiran dan standar internasional dalam memimpin dan mengendalikan teknologi informasi di sebuah perusahaan. TI yang efektif dapat membantu memastikan bahwa TI mendukung tujuan bisnis, mengoptimalkan bisnis melalui investasi di TI, dan mengelola resiko dan peluang yang berkaitan dengan TI. ITGI menawarkan penelitian, sumber daya elektronik dan studi kasus untuk membantu para pemimpin perusahaan dan dewan direksi di dalam tata kelola TI mereka. ITGI telah merancang dan menciptakan sebuah publikasi berjudul COBIT (Control Objectives for Information and related Technology) sebagai sarana dan sumber daya edukasi untuk Chief Information Officer (CIO), manajemen senior, manajemen TI dan para professional yang bertugas melakukan kendali. COBIT dikembangkan oleh IT Governance Institute, yang merupakan bagian dari Information Systems Audit and Control Association (ISACA).

Tema utama dari COBIT adalah orientasi bisnis. COBIT dirancang untuk digunakan tidak hanya oleh pengguna dan auditor, tetapi juga, dan yang lebih penting sebagai pedoman yang komprehensif bagi manajemen dan pemilik business process. Semakin praktik bisnis melibatkan pemberdayaan yang penuh dari pemilik business process, maka mereka memiliki tanggung jawab penuh untuk semua aspek dari business process, khususnya termasuk melakukan pengawasan yang memadai. Framework ini dimulai dari premis sederhana dan pragmatis untuk memberikan informasi yang diperlukan organisasi untuk mencapai tujuannya, sumber daya TI harus dikelola oleh serangkaian proses alami yang telah dikelompokkan.

Pedoman tata kelola TI juga disediakan di dalam framework COBIT. Tata kelola TI menyediakan struktur yang menghubungkan proses TI, sumber daya TI dan informasi untuk strategi dan tujuan perusahaan. Tata kelola TI mengintegrasikan cara yang optimal dari planning and organizing, acquiring and implementing, delivering and supporting, serta monitoring and evaluating dari kinerja TI. Tata kelola TI memungkinkan perusahaan untuk mengambil keuntungan penuh dari informasi yang dimilikinya, sehingga memaksimalkan keuntungan, memanfaatkan peluang dan mendapatkan keuntungan kompetitif.

\section{II.6.5 PERBANDINGAN BEBERAPA MODEL AUDIT DENGAN COBIT}

Tabel 1. menunjukkan bahwa ITIL sangat fokus kepada proses desain dan implementasi TI, serta 
pelayanan pelanggan (customer service), hal ini diperlihatkan bahwa hampir seluruh proses pada domain AI dan DS COBIT dilakukan.

Tabel 1. Matriks Proses COBIT vs Standar ITIL

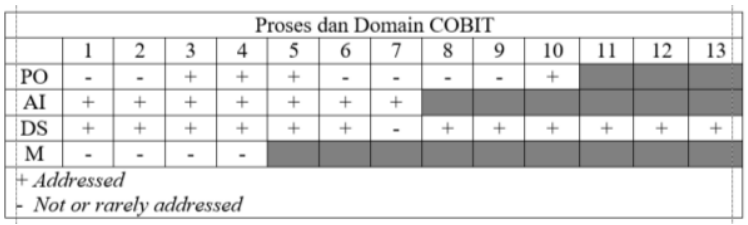

Sumber: (ISACA, 2006). COBIT MAPPING, Overview International IT Guidance, $2^{\text {nd }}$ Edition. IT Governance Institute: USA.

Sebagian proses PO dilakukan, ini menunjukkan bahwa ITIL tidak terlalu fokus pada proses penyelarasan strategi perusahaan dengan pengelolaan TI. Proses pada domain $M$ sama sekali tidak dilakukan oleh ITIL, hal ini menunjukkan ITIL tidak melakukan pengawasan yang akan memastikan kesesuaian pengelolaan TI dengan keadaan perusahaan di masa yang akan datang.

Tabel 2. menunjukkan bahwa ISO/IEC 17799 melakukan sebagian proses-proses pada seluruh domain COBIT.

\section{Tabel 2. Matriks Proses COBIT vs Standar ISO/IEC} 17799

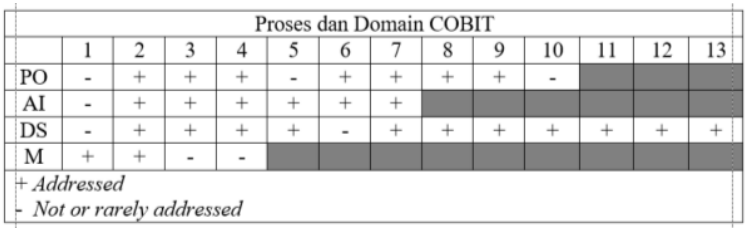

Sumber: (ISACA, 2006). COBIT MAPPING, Overview International IT Guidance, $2^{\text {nd }}$ Edition. IT Governance Institute: USA.

Hal ini menunjukkan ISO/IEC 17799 mempunyai spektrum yang luas dalam hal pengelolaan TI sebagaimana halnya COBIT, namun ISO/IEC 17799 tidak sedalam COBIT dalam hal detail proses-proses yang dilakukan dalam domaindomain tersebut.

Tabel 3. menunjukkan bahwa COSO melakukan sebagian proses di domain PO, AI dan DS, namun tidak satupun proses pada domain M dilakukan.
Tabel 3. Matriks Proses COBIT vs Standar COSO

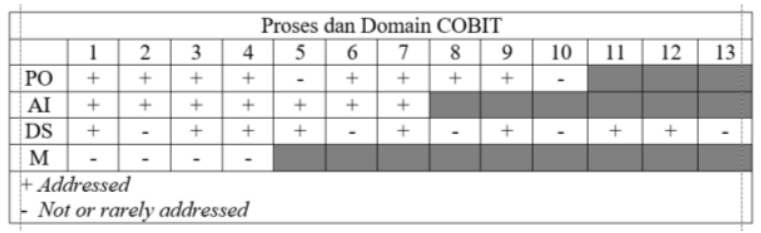

Sumber: (ISACA, 2006). COBIT MAPPING, Overview International IT Guidance, $2^{\text {nd }}$ Edition. IT Governance Institute: USA.

Hal ini menunjukkan bahwa COSO fokus kepada proses penyelarasan AI teknologi informasi dengan strategi perusahaan dan sangat fokus dalam hal desain dan implementasi teknologi informasi.

Tabel 4. memperlihatkan bahwa model-model standar selain COBIT tidak mempunyai range spectrum yang seluas COBIT. Model-model tersebut hanya melakukan sebagian dari proses-proses pengelolaan yang ada di dalam COBIT.

Tabel 4. Matriks Domain COBIT vs ITIL, ISO/IEC 17799 dan COSO

\begin{tabular}{|c|c|c|c|c|}
\hline \multirow{2}{*}{ Standar } & \multicolumn{4}{|c|}{ Domain COBIT } \\
\hline & $\mathrm{PO}$ & $\mathrm{AI}$ & DS & M \\
\hline ITIL & 0 & + & + & - \\
\hline ISO/IEC 17799 & ○ & + & + & 0 \\
\hline $\mathrm{COSO}$ & + & + & o & - \\
\hline $\begin{array}{l}+ \text { Frequently add } \\
- \text { Moderately ad } \\
\text { - Not or rarely a }\end{array}$ & $\begin{array}{l}\text { ed } \\
\text { sed } \\
\text { essed }\end{array}$ & & & \\
\hline
\end{tabular}

Gambar 2 memetakan standar COBIT dengan standar lainnya dalam hal kelengkapan proses-proses TI yang dilihat dalam dua dimensi yaitu:

1. Vertical - melihat kedetailan atau kedalaman standar dalam hal teknis dan operasional.

2. Horizontal - melihat kelengkapan proses-proses TI. 


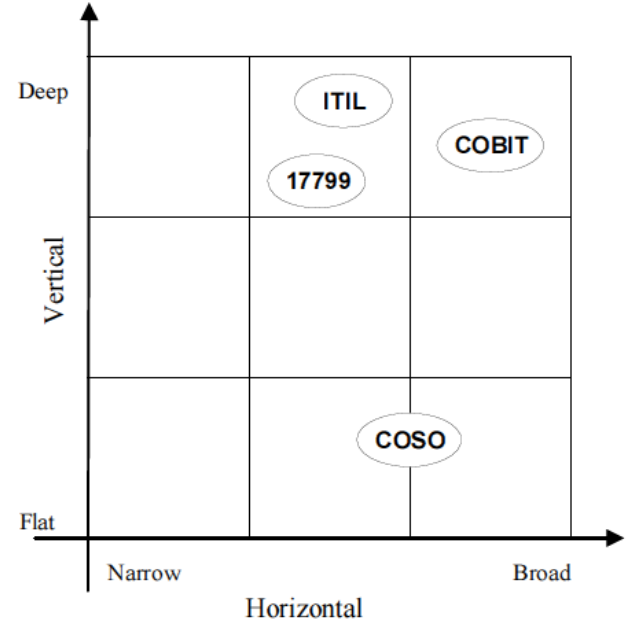

Gambar 2. Pemetaan COBIT Terhadap ITIL, ISO/IEC 17799 dan COSO (ISACA, 2006).

Dalam gambar 2 tersebut dapat dilihat bahwa COBIT mempunyai kompromi antara dimensi horizontal dan vertical yang lebih baik dari standarstandar lainnya. COBIT mempunyai spektrum proses TI yang lebih luas dan lebih detail. ITIL merupakan standar yang paling mendetail dan mendalam pada pendefinisian proses-proses TI yang bersifat teknis dan operasional. Sedangkan COSO mempunyai detail yang dangkal, walaupun spektrum proses teknis dan operasionalnya cukup luas.

\section{II.7 COBIT Framework}

COBIT adalah salah satu model IT governance framework berstandar internasional yang representatif dan holistik. COBIT dikembangkan oleh IT Governance Institute (ITGI) yang berbasis di Amerika Serikat yang mencakup masalah perencanaan, implementasi, operasional dan pengawasan terhadap seluruh proses TI.

Prinsip dasar framework secara ringkas adalah IT resources dikelola oleh IT processes untuk mencapai IT goals yang menjawab persyaratan bisnis. Di dalam kerangka kerja COBIT terhadap tujuh persyaratan atau kriteria informasi bisnis yaitu effectiveness, efficiency, integrity, confidentiality, availability, compliance dan reliability. COBIT kemudian menjelaskan bahwa sumber daya TI yang harus disediakan untuk memberikan kebutuhan bisnis oleh proses bisnis yaitu applications, information, infrastructure dan people seperti tampak dalam gambar 3 :

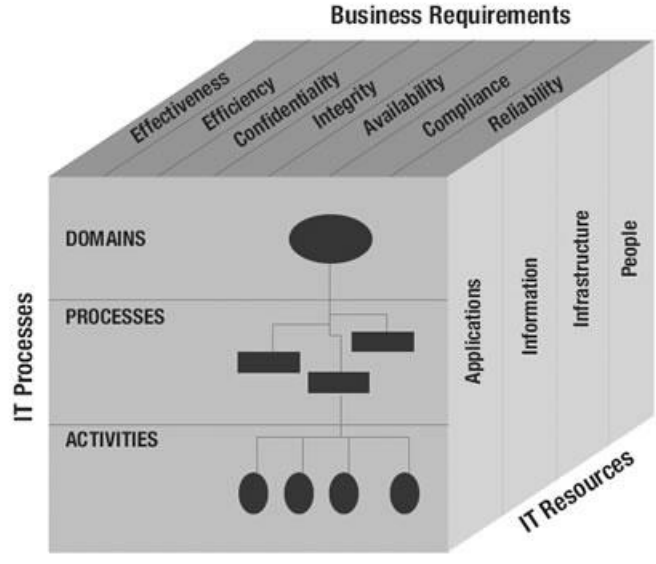

Gambar 3. The COBIT Cube (ISACA, 2007)

COBIT mendefinisikan aktivitas individual di dalam lingkungan TI ke dalam 34 proses yang dikelompokam ke dalam empat domain yaitu Plan and Organize (10 proses), Acquire and Implement (7 proses), Deliver and Support (13 proses) dan Monitor and Evaluate (4 proses).

COBIT memiliki beberapa karakteristik yaitu berfokus pada bisnis (business-focused), berorientasi pada proses (process-oriented), berbasis pada pengendalian (controls-based) dan terarah kepada pengukuran (measurement-driven).

Model Kematangan (Maturity Models) adalah alat bantu yang dapat digunakan untuk melakukan benchmarking dan self-assessment oleh manajemen TI untuk menilai kematangan proses TI. Dengan Model Kematangan, manajemen dapat mengidentifikasi:

a. Kinerja aktual dari perusahaan untuk mengetahuai posisi perusahaan pada saat ini.

b. Status industri saat ini sebagai bahan perbandingan.

c. Target perbaikan bagi perusahaan untuk mengetahui kemana perusahaan ingin dibawa.

d. Jalur pertumbuhan yang diperlukan antara "asis" dan "to-be".

Secara umum, tingkat kematangan proses TI dibagi menjadi enam tingkat, mulai dari tingkat kematangan 0 - Non Existent, 1 - Initial/Ad Hoc, 2 Repeatable but Intuitive, 3 -Defined, 4 - Managed and Measurable dan 5 - Optimised. 
Selain keenam tingkatan tersebut di atas, Tingkat Kematangan disusun oleh atribut-atribut sebagai berikut:

a. Awareness and Communication (CA);

b. Policies, Standards and Procedures (PSP);

c. Tools and Automation (TA);

d. Skills and Expertise (SE);

e. Responsibility and Accountability (RA); dan

f. Goal Setting and Measurement (GSM)

\section{Metodologi Penelitian}

Penelitian ini dilakukan dengan menggunakan data primer dan sekunder. Dimana data primer diperoleh dari kuesioner kepada responden. Data primer ini adalah pendapat responden atas layanan sistem informasi yang diberikan oleh Sub Bagian Jasa dan Informasi Puslit Telimek LIPI dalam memenuhi kewajibannya. Pemilihan responden dilakukan dengan purposive sampling yang artinya proses pengambilan sampel dilakukan secara sengaja sesuai dengan persyaratan sampel yang dibutuhkan.

Sementara itu data sekunder diperoleh dari hasil wawancara, studi pustaka, observasi, mempelajari dokumen yang berkaitan dengan layanan sistem informasi di Sub Bagian Jasa dan Informasi Puslit Telimek LIPI.

Penelitian dilakukan dengan menggunakan metode survey. Data deskriptif digunakan sebagai dasar pembuatan keputusan. Pengumpulan datanya dilakukan dengan menggunakan kuesioner. Desain penelitian merupakan riset deskriptif yang menggambarkan suatu kondisi pada suatu waktu uji. Riset deskriptif meliputi survey dan pencarian fakta. Penelitian ini bersifat cross-sectional study artinya informasi yang dikumpulkan hanya pada periode waktu tertentu saja. Hasil dari penelitian dapat dijadikan acuan dalam memutuskan perbaikan. Hal ini sesuai dengan rumusan masalahnya yaitu melakukan evaluasi dan memberikan rekomendasi atas hasil penelitian.

Teknik pengumpulan data bersifat self administered survey dimana pegawai diminta mengisi sendiri kuesioner yang diberikan. Penyebaran kuesioner dilakukan kepada responden secara langsung dalam beberapa hari kerja. Kuesioner yang diberikan bersifat closed ended questions dimana bentuk pertanyaan diikuti dengan beberapa alternatif jawaban bagi pegawai.
Setiap pernyataan yang terdapat di dalam kuesioner mengacu kepada kontrol objectif sub dari setiap modul yang terdapat di dalam domain Deliver and Support dari framework COBIT. Kuesioner penelitian ini meminta responden untuk memberikan pendapatnya mengenai layanan sistem informasi di Sub Bagian Jasa dan Informasi Puslit Telimek LIPI dalam bentuk skala sikap. Dimana skala Likert yang digunakan terdiri dari lima tingkatan bobot yaitu Sangat Tidak Setuju (bobot $=1$ ), Tidak Setuju (bobot $=2)$, Tidak Tahu (bobot $=0)$, Setuju $($ bobot $=4)$ dan Sangat Setuju (bobot $=5$ ).

Indeks Kematangan Atribut setiap modul domain diperoleh dari menjumlahkan jumlah responden yang menjawab untuk setiap skala sikap pada setiap modul DS dikalikan dengan bobot skala kemudian dibagi dengan jumlah responden seperti berikut ini:

$$
\text { Indeks Kematangan Atribut }=\frac{\sum(\text { Total Jawaban* Bobot })}{\text { Jumlah Responden }}
$$

Setelah dilakukan penghitungan Indeks Kematangan, maka akan didapat tingkat kematangan untuk masing-masing sub domain yang ada pada domain Deliver and Support dengan mengacu kepada tabel di bawah ini.

Tabel 5. Representasi Tingkat Kematangan COBIT

\begin{tabular}{cl}
\hline \hline $\begin{array}{c}\text { Indeks } \\
\text { Kematangan }\end{array}$ & \multicolumn{1}{c}{ Level Kematangan } \\
\hline \hline $0.00-0.50$ & $0 \rightarrow$ Non-Existent \\
$0.51-1.50$ & $1 \rightarrow$ Initial / Ad Hoc \\
$1.51-2.50$ & $2 \rightarrow$ Repeatable But Intuitive \\
$2.51-3.50$ & $3 \rightarrow$ Defined Process \\
$3.51-4.50$ & $4 \rightarrow$ Managed and Measurable \\
$4.51-5.00$ & $5 \rightarrow$ Optimised \\
\hline \hline
\end{tabular}

\section{Hasil Penelitian dan Pembahasan}

Secara umum maturity level sistem informasi di Puslit Telimek LIPI dirata-ratakan dari setiap kategori dan didapat tingkat kematangan (maturity level) tata kelola sistem informasi di Puslit Telimek LIPI yang selengkapnya dapat dilihat pada tabel 6 : 
Tabel 6. Rata-rata Maturity Level Sistem Informasi di Puslit Telimek LIPI Menurut Responden Kategori Staf TU dan Peneliti

\begin{tabular}{clc}
\hline \hline Domain & \multicolumn{1}{c}{ Process } & $\begin{array}{c}\text { Current } \\
\text { Maturity }\end{array}$ \\
\hline \hline DS1 & Define and Manage Service Levels & 2.35 \\
DS2 & Manage Third-party Services & 2.16 \\
DS3 & Manage Performance and Capacity & 2.20 \\
DS4 & Ensure Continuous Service & 1.94 \\
DS5 & Ensure Systems Security & 2.08 \\
DS6 & Identify and Allocate Costs & 1.74 \\
DS7 & Educate and Train Users & 1.64 \\
DS8 & Manage Service Desk and & 1.92 \\
& Incidents & 1.56 \\
DS10 & Manage the Configuration & 1.69 \\
DS11 & Manage Problems Manage Data & 1.79 \\
DS12 & Manage the Physical Environment & 1.39 \\
DS13 & Manage Operations & 1.44 \\
\hline \hline
\end{tabular}

Sedangkan dari tabel di atas dimana tingkat kematangan (maturity level) Domain Deliver and Support dapat dibuat representasinya dalam grafik radar, seperti yang terlihat pada gambar 4 :

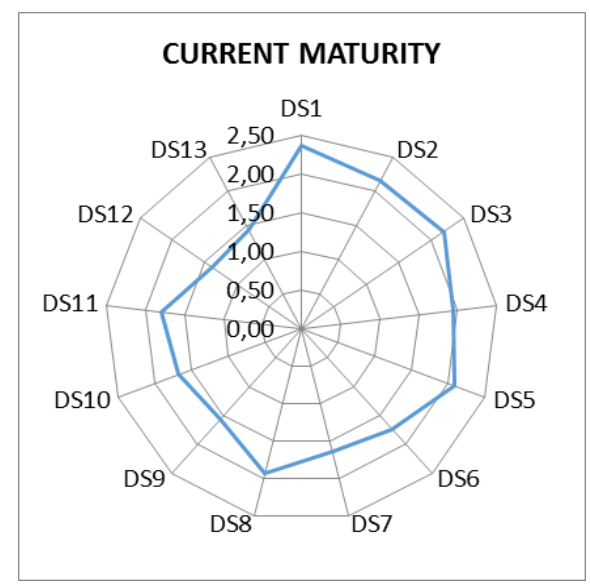

Gambar 4. Grafik Radar Tingkat Kematangan Sistem Informasi di Puslit Telimek LIPI Untuk Domain Deliver And Suppor
Tabel 7. Nilai Maturity Sistem Informasi di Puslit Telimek LIPI Menurut Responden Kategori Staf TU Dan Peneliti

\begin{tabular}{ccc}
\hline \hline Domain & Kategori & Maturity \\
\hline \hline DS & Staf TU & 1.96 \\
DS & Peneliti & 1.72 \\
\hline \multicolumn{2}{c}{ Nilai Maturity Menurut Staf TU dan } \\
Peneliti & 1.84 \\
\hline \hline
\end{tabular}

Dari tabel 7 dapat dilihat bahwa rata-rata tingkat kematangan saat ini (current maturity level) untuk Domain Deliver and Support berada di sekitar level 2 (Repeatable but Intuitive). Dimana proses dikembangkan ke dalam tahapan-tahapan dengan prosedur yang serupa dan diikuti oleh pihak-pihak yang berbeda untuk pekerjaan yang sama. Tidak ada pelatihan secara formal atau pengkomunikasian prosedur standar, dan tanggung jawab diserahkan kepada individu. Sangat tergantung pada pengetahuan individu, dan oleh karena itu mungkin sekali terjadi kesalahan.

\section{KESIMPULAN DAN SARAN}

Dari hasil penelitian diperoleh kesimpulan bahwa proses DS1, DS2, DS3, DS4, DS5, DS6, DS7, DS8, DS9, DS10 dan DS11 pada Domain Deliver and Support yang diberikan penyedia sistem informasi kepada Puslit Telimek LIPI secara umum berada pada tingkat kematangan Repeatable but Intuitive, yaitu proses telah dikembangkan ke dalam tahapan prosedur yang diikuti oleh pihak-pihak yang berbeda untuk pekerjaan yang sama. Tidak terdapat pelatihan formal atau pengkomunikasian prosedur standar, tanggung jawab diserahkan kepada individu masing-masing. Terdapat tingkat kepercayaan yang tinggi terhadap pengetahuan individu sehingga kemungkinan terjadi kesalahan sangat besar.

Proses DS12 dan DS13 pada Domain Deliver and Support yang diberikan penyedia sistem informasi kepada Puslit Telimek LIPI secara umum berada pada tingkat kematangan Initial/Ad Hoc, yaitu terdapat bukti bahwa lembaga mengetahui adanya permasalahan yang harus diatasi, namun tidak terdapat proses standar dalam penyelesaiannya, melainkan menggunakan pendekatan ad hoc yang cenderung diperlakukan secara individu atau per 
kasus. Secara umum pendekatan kepada pengelolaan proses tidak terorganisasi dengan baik.

\section{REFERENSI}

Barve, Jitendra. (2010). COBIT for IT Risk Management in a Bank - A Case Study. ICASA: USA.

Deeson, Eric. (1991). Dictionary of Information Technology. Harper Collins Publishers: Glasgow.

Gomes, R., Ribeiro, J. (2009). The Main Benefits of COBIT in a High Public Educational Institution - A Case Study. Pacific Asia Conference on Information Systems. Universitat Trier: Jerman.

Gondodiyoto, Sanyoto. (2007). Audit Sistem Informasi + Pendekatan COBIT. Penerbit Mitra Wacana Media: Jakarta.

ISACA. (2000). COBIT $3^{\text {rd }}$ Edition, Audit Guidelines. IT Governance Institute: USA.

ISACA. (2000). COBIT $3^{\text {rd }}$ Edition, Implementation Tool Set. IT Governance Institute: USA.

ISACA. (2000). COBIT $3^{\text {rd }}$ Edition, Management Guidelines. IT Governance Institute: USA.

ISACA. (2004). Board Briefing on IT Governance, $2^{\text {nd }}$ Edition. IT Governance Institute: USA.

ISACA. (2006). COBIT MAPPING, Overview International IT Guidance, $2^{\text {nd }}$ Edition. IT Governance Institute: USA.

ISACA. (2007). COBIT 4.1. IT Governance Institute: USA.

Kadir, Abdul. (2003). Pengenalan Sistem Informasi. Andi Offset: Yogyakarta.

Sarno, Riyanarto. (2009). Audit Sistem dan Teknologi Informasi. ITS Press: Surabaya.

Weber, Ron. (1999). Information System Control and Audit. Prentice-Hall: Queensland. 